\title{
Noninvasive methods, including transient elastography, for the detection of liver disease in adults with cystic fibrosis
}

\author{
Matthew D Sadler MD FRCPC ${ }^{1}$, Pam Crotty MSc ${ }^{1}$, Linda Fatovich MN², Stephanie Wilson MD FRCPC ${ }^{3}$,
}

Harvey R Rabin MD FRCPC ${ }^{2}$, Robert P Myers MD MSc FRCPC ${ }^{1,4}$

MD Sadler, P Crotty, L Fatovich, S Wilson, HR Rabin, RP Myers.

Noninvasive methods, including transient elastography, for the detection of liver disease in adults with cystic fibrosis. Can J Gastroenterol Hepatol 2015;29(3):139-144.

BACKGROUND: Liver disease is the third leading cause of mortality in patients with cystic fibrosis (CF). However, detection of $\mathrm{CF}$-associated liver disease (CFLD) is challenging.

OBJECTIVE: To evaluate the diagnostic performance of noninvasive methods for the detection of CFLD with a focus on transient elastography (TE).

METHODS: Patients at the Adult CF Clinic of Calgary and Southern Alberta $(n=127)$ underwent liver stiffness measurement (LSM) by TE using the FibroScan (FS, Ecosens, France) M probe; aspartate aminotransferase to platelet ratio index (APRI) and FibroTest (FT) scores were also calculated. The diagnostic performance of these tools for the detection of CFLD (defined as two or more the following criteria: abnormal liver biochemistry, hepatomegaly or sonographic abnormalities other than steatosis) were compared using the area under ROC curves. RESULTS: Forty-seven percent of the cohort was male. The median age was 27 years (interquartile range [IQR] 22 to 37 years) and body mass index $21 \mathrm{~kg} / \mathrm{m}^{2}$ (IQR $19 \mathrm{~kg} / \mathrm{m}^{2}$ to $23 \mathrm{~kg} / \mathrm{m}^{2}$ ); $25 \%$ of patients were on ursodeoxycholic acid and $12 \%$ had undergone lung transplantation. The prevalence of CFLD was $14 \%(n=18)$. FS was successful in all patients; one $(0.8 \%)$ patient had poorly reliable results $(\mathrm{IQR} / \mathrm{M}$ $>30 \%$ and $L S M \geq 7.1 \mathrm{kPa}$ ). Compared with patients without CFLD $(\mathrm{n}=109)$, individuals with CFLD had higher median LSM according to FS (3.9 kPa [IQR 3.4 to $4.9 \mathrm{kPa}$ ] versus $6.4 \mathrm{kPa}$ [IQR 4.4 to $8.0 \mathrm{kPa}$ ), APRI (0.24 [IQR 0.17 to 0.31 ] versus 0.50 [IQR 0.22 to 1.18 ]) and FT scores (0.08 [IQR 0.05 to 1.5 ] versus 0.18 [IQR 0.11 to 0.35]; all $\mathrm{P}<0.05)$. Area under ROC curve for FS, APRI and FT for the detection of CFLD were 0.78 (95\% CI 0.65 to 0.92), 0.72 (95\% CI 0.56 to 0.87 ) and 0.76 (95\% CI 0.62 to 0.90 ) (P not significant). At a threshold of $>5.2 \mathrm{kPa}$, the sensitivity, specificity, positive and negative predictive values of LSM according to FS for detecting CFLD were $67 \%$, $83 \%, 40 \%$ and $94 \%$, respectively.

CONCLUSIONS: FS, APRI and FT were useful noninvasive methods for detecting CFLD in adults.

Key Words: Cystic fibrosis; FibroTest; Transient elastography

\section{Les méthodes non invasives, y compris l'élastographie transitoire, pour déceler les maladies hépatiques chez les adultes atteints de fibrose kystique}

HISTORIQUE : Les maladies hépatiques sont la troisième cause de mor talité en importance chez les patients atteints de fibrose kystique (FK). Il est toutefois difficile de dépister les maladies hépatiques qui s'associent à la FK (MHFK).

OBJECTIF : Évaluer le rendement diagnostique de méthodes non invasives pour déceler les MHFK, en s'attardant sur l'élastographie transitoire (ÉT). MÉTHODOLOGIE : Les patients de la clinique de FK pour adultes de Calgary et du sud de l'Alberta $(\mathrm{n}=127)$ ont subi une mesure de dureté du foie (MDF) par ÉT au moyen de la sonde M de FibroScan (FS, Ecosens, France). Les chercheurs ont également calculé le score de l'indice du ratio entre l'aspartate-aminotransférase et les plaquettes (APRI) et le score du FibroTest (FT). Ils en ont comparé le rendement diagnostique pour déceler la MHFK (définie comme au moins deux des critères suivants : biochimie hépatique anormale, hépatomégalie ou autres anomalies sonographiques qu'une stéatose) à l'aide des surfaces sous la courbe ROC.

RÉSULTATS : La cohorte, dont $47 \%$ étaient de sexe masculin, avait un âge médian de 27 ans (plage interquartile [PIQ] de 22 à 37 ans) et un indice de masse corporelle de $21 \mathrm{~kg} / \mathrm{m}^{2}$ (PIQ de $19 \mathrm{~kg} / \mathrm{m}^{2}$ à $23 \mathrm{~kg} / \mathrm{m}^{2}$ ). De plus, $25 \%$ des patients prenaient de l'acide ursodésoxycholique et $12 \%$ avaient subi une transplantation pulmonaire. La prévalence de MHFK était de $14 \%$ $(\mathrm{n}=18)$. La FS a pu être exécutée chez tous les patients, mais les résultats d'un patient $(0,8 \%)$ étaient peu fiables (PIQ/M $>30 \%$ et $\mathrm{MDF} \geq 7,1 \mathrm{kPa}$ ). Par rapport aux patients sans MHFK $(\mathrm{n}=109)$, ceux ayant une MHFK présentaient une MDF médiane plus élevée selon la FS (3,9 kPa [PIQ 3,4 à $4,9 \mathrm{kPa}$ ] par rapport à $6,4 \mathrm{kPa}$ [PIQ 4,4 à $8,0 \mathrm{kPa}$ ]), et les scores d'APRI $(0,24$ [PIQ 0,17 à 0,31 ] par rapport à 0,50 [PIQ 0,22 à 1,18 ]) et de FT $(0,08$ [PIQ 0,05 à 1,5] par rapport à 0,18 [PIQ 0,11 à 0,35 ]; tous les $\mathrm{P}<0,05)$. La surface sous la courbe ROC de la FS, de l'APRI et du FT pour déceler la MHFK correspondait à 0,78 (95\% IC 0,65 à 0,92), 0,72 (95\% IC 0,56 à 0,87 ) et 0,76 (95\% IC 0,62 à 0,90 ) (P non significatif). À un seuil de plus de $5,2 \mathrm{kPa}$, la sensibilité, la spécificité et les valeurs prédictives positives et négatives de la MDF par FS pour déceler la MHFK s'élevaient à $67 \%, 83 \%, 40 \%$ et $94 \%$, respectivement.

CONCLUSIONS : La FS, l'APRI et le FT se sont révélés des méthodes non invasives utiles pour déceler la MHFK chez les adultes.

$\mathrm{H}$ epatobiliary manifestations of cystic fibrosis (CF) are variable, but include alterations attributable to the underlying genetic defect, malnutrition, lesions of iatrogenic origin and changes that reflect the effects of a systemic disease. Focal biliary cirrhosis due to biliary obstruction with progressive periportal fibrosis is the most clinically relevant problem because multilobular biliary cirrhosis, portal hypertension and, eventually, liver failure may develop (1). In fact, successes in the management of CF-related respiratory and nutritional complications have resulted in an increased recognition of liver disease, which now ranks as the third leading cause of mortality in patients with CF (1).

Unfortunately, several challenges exist in the identification of $\mathrm{CF}$-associated liver disease (CFLD) given the wide spectrum of hepatic complications associated with this condition. Standard screening using physical examination, liver biochemistry and abdominal ultrasound imaging lacks sensitivity for early hepatic involvement in $\mathrm{CF}$ and for predicting who is at risk for progression to cirrhosis (2). As such, liver biopsy remains the gold standard for diagnosing and staging hepatic fibrosis in patients with CF. However, there are several limitations with the routine use of liver biopsy, including the focal nature of early CF-related lesions, which may lead to sampling error and subjectivity in histological interpretation. Moreover, the invasiveness of

${ }^{1}$ Liver Unit, Division of Gastroenterology and Hepatology; ${ }^{2}$ Adult Cystic Fibrosis Clinic of Calgary and Southern Alberta, Department of Medicine;

${ }^{3}$ Department of Radiology and Diagnostic Imaging; ${ }^{4}$ Department of Community Health Sciences, University of Calgary, Calgary, Alberta

Correspondence: Dr Robert P Myers, Liver Unit, University of Calgary, 6D22, Teaching, Research and Wellness Building, 3280 Hospital Drive

Northwest, Calgary, Alberta T2N 426. Telephone 403-592-5049, fax 403-592-5090, e-mail rpmyers@ucalgary.ca

Received for publication December 2, 2014. Accepted December 5, 2014 
liver biopsy makes it difficult to repeat for monitoring of changes in fibrosis over time (3). Importantly, the procedure carries a small - but real - risk for complications including hemorrhage and death $(4,5)$.

Given these limitations, alternative means of identifying CFLD and monitoring for disease progression are needed. Noninvasive serum and imaging-based methods of liver fibrosis evaluation may have a role in this patient population. Preliminary data suggest that liver stiffness measurement (LSM) using transient elastography (TE) (FibroScan [FS], Echosens, France) and serum biomarkers (eg, the aspartate aminotransferase [AST] to platelet ratio index [APRI] and FibroTest [FT; Biopredictive, France]) hold promise (6-10). A novel technique known as acoustic radiation force impulse (ARFI) imaging (Virtual Touch Tissue Quantification, Acuson S2000, Siemens, USA) has also been studied $(7,11,12)$. This elastographic method, which is incorporated in a conventional ultrasound device, uses acoustic pulses to generate a shear wave in the liver. The velocity of shear wave propagation (measured in $\mathrm{m} / \mathrm{s}$ ) is proportional to liver fibrosis determined histologically.

Because data regarding the use of these noninvasive fibrosis methods in patients with CF are limited, our objective was to assess their feasibility and diagnostic performance for the detection of CFLD, with an emphasis on LSM using TE. In addition, our unique clinical setting enabled us to determine the prevalence of liver disease in a population-based cohort of adults with CF.

\section{METHODS}

\section{Study population}

All adult patients ( $\geq 18$ years of age) with CF followed at the Adult CF Clinic of Calgary and Southern Alberta were recruited for the present study between April 2010 and April 2011. The Adult CF Clinic is a multidisciplinary clinic that cares for all adults with CF in southern Alberta and a small number of patients from southeastern British Columbia and Saskatchewan. The catchment population of Calgary is approximately 1.2 million, with a reported CF prevalence of 11 to 12 cases per 100,000 population (13). Patients with serological evidence of chronic hepatitis B or hepatitis C were excluded. The Conjoint Health Research Ethics Board at the University of Calgary (Calgary, Alberta) approved the research protocol.

\section{Clinical data}

At enrollment, patient demographics, anthropometric measurements (weight, height, body mass index [BMI]), CF transmembrane regulator (CFTR) genetic mutations ( $\triangle \mathrm{F} 508)$, ursodeoxycholic acid (UDCA) use and history of CF-related complications, including pancreatic exocrine insufficiency, diabetes mellitus and lung transplantation, were recorded. Pancreatic exocrine insufficiency was defined as severe malabsorption responding to pancreatic enzyme supplementation. All patients underwent a standard physical examination and routine laboratory investigations. Individuals with examination findings suggestive of liver disease or abnormal liver biochemistry underwent abdominal ultrasonography $(n=78)$. The following laboratory investigations were performed: complete blood count, alanine aminotransferase, AST, gamma-glutamyl transferase (GGT), alkaline phosphatase (ALP), total bilirubin, albumin, creatinine, random glucose, international normalized ratio, haptoglobin, apolipoprotein A1 and alpha2 -macroglobulin. Spirometry values from pulmonary function testing on the day of enrollment were also recorded.

The primary outcome measure was CFLD defined according to previously published criteria $(1,2)$. Specifically, CFLD was based on the presence of at least two of the following: clinical hepatomegaly and/or splenomegaly confirmed by ultrasonography; abnormal liver biochemistry consisting of elevated levels of any two of AST, ALT or GGT; and ultrasound abnormalities other than hepatomegaly (ie, increased heterogeneous echogenicity, nodularity of the liver surface, irregular margins, splenomegaly, presence of portosystemic collateral veins and ascites) $(1,2,6)$. Ultrasonographic evidence of steatosis was not a diagnostic criterion. Liver biopsies are not routinely performed in the authors' clinic.

\section{LSM}

Two experienced operators performed all LSMs with TE using the FS, as previously described (14). The FS M probe was used in all patients except one, in whom the XL probe was used. Briefly, with the patient lying in the dorsal decubitus position, the tip of the transducer was placed on the skin between the ribs over the right lobe of the liver. An attempt was made to collect at least 10 valid LSMs, and the median LSM (in $\mathrm{kPa}$ ) was considered to be representative of the elastic modulus of the liver. FS failure was defined as no valid LSMs after at least 10 attempts. LSMs $\geq 7.1 \mathrm{kPa}$ with an interquartile range (IQR) to median LSM ratio (IQR/M) $>30 \%$ were considered to be poorly reliable as defined by Boursier et al (15). In a subset of patients ( $n=18)$, ARFI imaging was used to determine hepatic shear wave velocity (SWV) based on the median of 12 measurements taken from the right lobe of the liver (in m/s; range $0.5 \mathrm{~m} / \mathrm{s}$ to $5.5 \mathrm{~m} / \mathrm{s}$ ). A single experienced radiologist performed all ARFI measurements as previously described (11).

\section{Serum markers of liver fibrosis}

The APRI was calculated as follows $(9,10)$ :

$$
\begin{gathered}
\text { APRI }=(\text { AST/upper limit of normal for AST }) \times \\
\left(100 / \text { platelets }\left[\times 10^{9} / \mathrm{L}\right]\right)
\end{gathered}
$$

The FT was calculated based on age, sex, GGT, total bilirubin, alpha-2-macroglobulin, apolipoprotein A1 and haptoglobin (16-19).

Both the APRI and FT were developed in patients with chronic hepatitis $\mathrm{C}$, but have been validated in other liver disorders including CFLD (20-22).

\section{Statistical analyses}

Between-group comparisons were made using Fisher's exact and MannWhitney tests, and Spearman correlation coefficients were calculated between results of the noninvasive measures. The diagnostic performance of LSM according to TE, ARFI, APRI and FT for CFLD were determined using areas under ROC curves (AUROC). Comparisons between diagnostic methods (restricted to patients in whom all of the relevant tests had been performed) were made using the nonparametric method described by DeLong et al (23). Finally, the sensitivity, specificity, accuracy, positive predictive value (PPV) and negative predictive value (NPV) values of these tools were calculated with exact binomial 95\% CIs. For these analyses, optimal thresholds defined by the maximal sum of sensitivity and specificity were calculated. Stata version 11.0 (StataCorp, USA) was used for all statistical analyses. A two-sided $\mathrm{P}<0.05$ were considered to be statistically significant.

\section{RESULTS}

Patient characteristics and prevalence and predictors of CFLD The characteristics of the study cohort $(n=127)$ are summarized in Table 1. Forty-seven percent of the patients were male and the median age and BMI were 27 years (IQR 22 to 37 years) and $21 \mathrm{~kg} / \mathrm{m}^{2}$ (IQR $19 \mathrm{~kg} / \mathrm{m}^{2}$ to $23 \mathrm{~kg} / \mathrm{m}^{2}$ ), respectively. Only three (2.5\%) patients were obese (BMI $\geq 30 \mathrm{~kg} / \mathrm{m}^{2}$ ). The majority $(84 \%)$ of patients had pancreatic insufficiency, $12 \%$ had undergone lung transplantation and $25 \%$ were prescribed UDCA (median daily dosage, $1000 \mathrm{mg}$ [IQR $1000 \mathrm{mg}$ to $1375 \mathrm{mg}]$ ). Most (90\%) patients had the $\Delta$ F508 CF mutation (53\% were homozygous).

CFLD was present in $18(14 \%)$ patients. More patients with CFLD than those without CFLD were prescribed UDCA (83\% versus 14\%; $\mathrm{P}<0.00005)$. However, there were no significant differences between groups with respect to the prevalence of diabetes mellitus, pancreatic insufficiency, previous lung transplantation, pulmonary spirometry or the $\Delta \mathrm{F} 508$ mutation (heterozygous or homozygous). As expected, patients with CFLD had higher median serum ALT, AST, GGT, alkaline phosphatase and bilirubin levels, and international normalized ratio values (Table 1 ).

Detection of CFLD using TE, ARFI and serum markers of fibrosis All patients underwent a successful LSM with TE using the FibroScan (ie, $0 \%$ failure rate. A poorly reliable result was obtained in only one 
TABLE 1

Characteristics of the cohort according to the presence of cystic fibosis-related liver disease (CFLD)

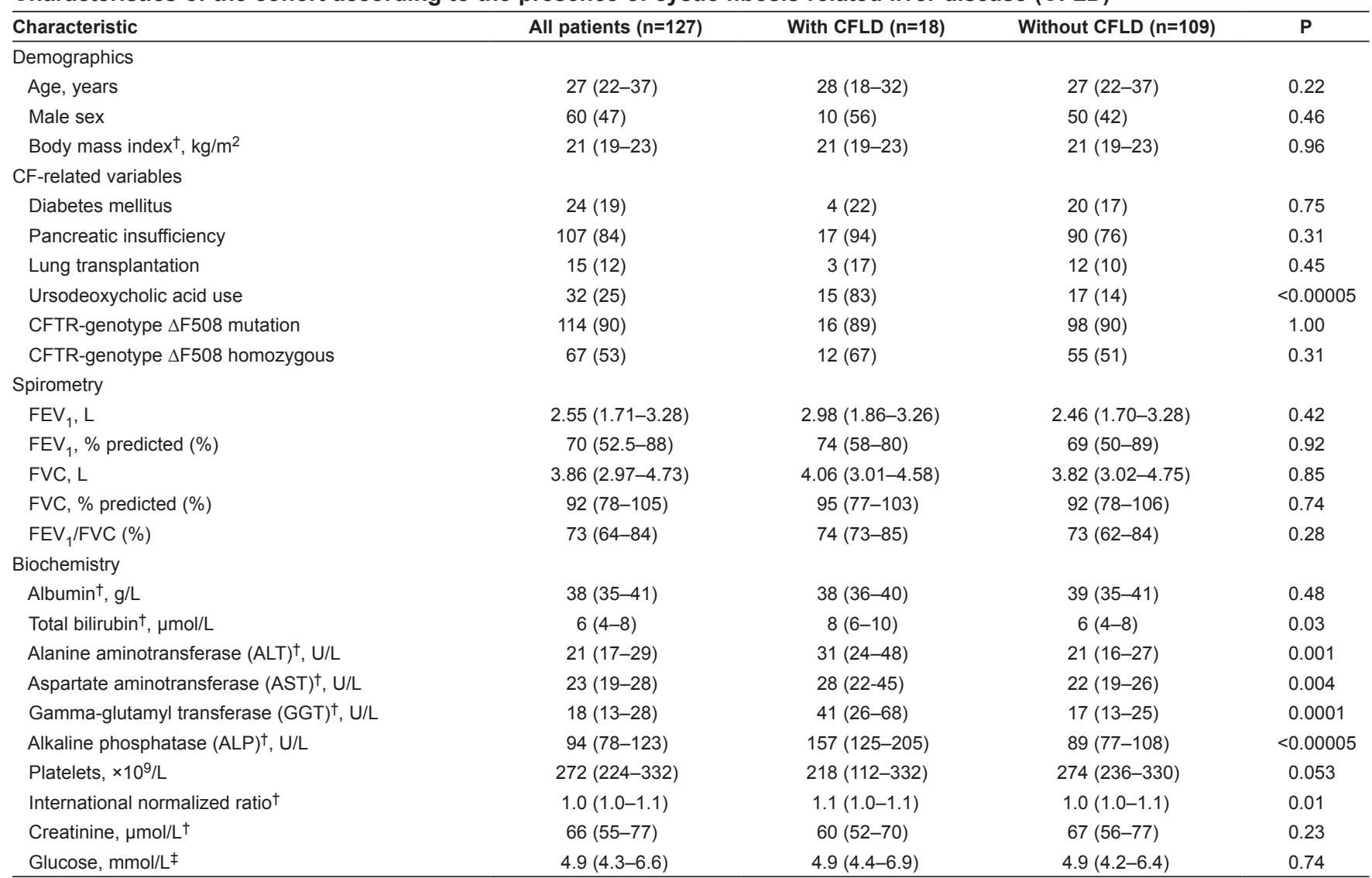

Data presented as $n(\%)$ or median (interquartile range). ${ }^{\dagger}$ Data missing for five patients (four without CFLD and one with CFLD). ${ }^{\ddagger} A l b u m i n$, total bilirubin, $A L T$, AST, GGT, ALP, international normalized ratio and creatinine missing in 1, 1, 1, 5, 1, 1, 4 and 1 patients (all in the group without CFLD), respectively; $¥$ Glucose data missing in 11 patients (one with CFLD). FEV 1 Forced expiratory volume in $1 \mathrm{~s}$; FVC Forced vital capacity

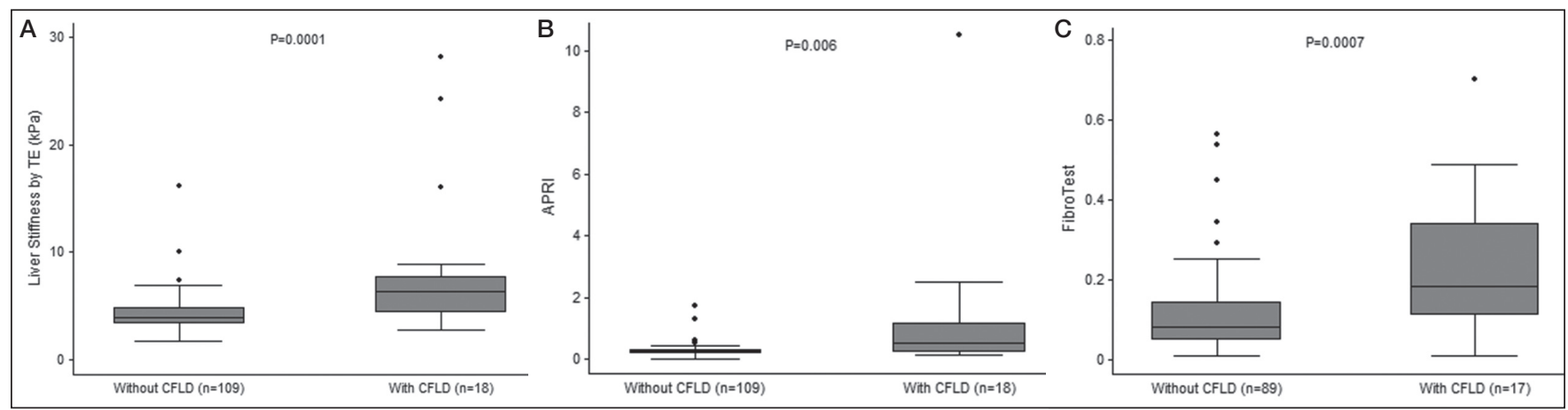

Figure 1) Liver stiffness measurement using transient elastography (TE; FibroScan, Ecosens, France) (A), aspartate aminotransferase to platelet ratio index (APRI) (B) and FibroTest (Biopredictive, France) (C) according to the presence or absence of cystic fibrosis-related liver disease (CFLD)

patient $(0.8 \%)$ who was severely obese (BMI $\left.35 \mathrm{~kg} / \mathrm{m}^{2}\right)$. In this patient - in whom CFLD was not diagnosed - the median LSM was $16.1 \mathrm{kPa}$ using the FibroScan M probe and the IQR/M was $41 \%$, indicating high measurement variability. Overall, $118(93 \%)$ patients had at least 10 valid LSMs using TE (success rate $\geq 60 \%$ ) and IQR/M $\leq 30 \%$.

As shown in Figure 1 and Table 2, median LSM according to TE was significantly higher in patients with than those without CFLD $(6.4 \mathrm{kPa}$ [IQR 4.4 to $7.7 \mathrm{kPa}$ ] versus $3.9 \mathrm{kPa}$ [IQR 3.4 to $4.9 \mathrm{kPa}$ ]; $\mathrm{P}=0.0001)$. Hepatic SWV measured using ARFI was available for 18 patients, three of whom had CFLD. Median SWV was not significantly different between patients with $(1.50 \mathrm{~m} / \mathrm{s}$ [IQR 0.99 to $1.50 \mathrm{~m} / \mathrm{s}])$ and without CFLD $(1.07 \mathrm{~m} / \mathrm{s}$ [IQR 1.01 to $1.10 \mathrm{~m} / \mathrm{s}])(\mathrm{P}=0.24)$. In contrast, median APRI (0.50 [IQR 0.22 to 1.17 ] versus 0.24 [IQR 0.17 to 0.31 ]; $\mathrm{P}=0.006$ ) and FT (0.18 [IQR 0.11 to 0.34 ] versus 0.08 [IQR 0.05 to 0.14 ]; $\mathrm{P}=0.0007$ ) values were significantly higher in patients with CFLD.

Liver stiffness according to TE was moderately correlated with FT $(\rho=0.32 ; P=0.001)$, but not APRI $(\rho=0.02 ; P=0.83)$ values. APRI and FT were weakly correlated $(\rho=0.20 ; P=0.04)$. SWV according to ARFI was moderately correlated with LSM according to TE $(\rho=0.31$; $\mathrm{P}=0.21)$ and FT $(\rho=0.42 ; \mathrm{P}=0.10)$; however, these correlations were not statistically significant.

Diagnostic accuracy of LSM according TE, ARFI and serum markers for CFLD

The AUROCs for LSM according TE, APRI and FT for the diagnosis of CFLD were 0.78 (95\% CI 0.65 to 0.92 [n=127]), 0.70 (95\% CI 
TABLE 2

Noninvasive markers of liver fibrosis in adults with cystic fibrosis-related liver disease (CFLD)

\begin{tabular}{|c|c|c|c|c|}
\hline Test & All patients & With CFLD & Without CFLD & $\mathbf{P}$ \\
\hline Liver stiffness measurement using transient elastography $(n=127)$ & $4.1(3.5-5.2)$ & $6.4(4.4-7.7)$ & $3.9(3.4-4.9)$ & 0.0001 \\
\hline FibroTest $^{\dagger}(n=106)$ & $0.09(0.06-0.18)$ & $0.18(0.11-0.34)$ & $0.08(0.05-0.14)$ & 0.0007 \\
\hline
\end{tabular}

Data presented as median (interquartile range) unless otherwise indicated. *Data missing for five patients (all without CFLD); ${ }^{+}$Biopredictive, France (data missing for 21 patients [one with CFLD and 20 without CFLD]); $¥$ Data available for 18 patients (three with CFLD and 15 without CFLD)

TABLE 3

Liver stiffness measurement (LSM) usung transient elastography (TE), aspartate aminotransferase to platelet ratio index (APRI) and FibroTest* for the diagnosis of cystic fibrosis-related liver disease

\begin{tabular}{|c|c|c|c|c|c|c|}
\hline & \multirow[b]{2}{*}{ AUROC } & \multirow[b]{2}{*}{ Sensitivity } & \multirow[b]{2}{*}{ Specificity } & \multicolumn{2}{|c|}{ Predictive value } & \multirow[b]{2}{*}{ Accuracy } \\
\hline & & & & Negative & Positive & \\
\hline \multicolumn{7}{|c|}{ LSM using TE $(n=127)$} \\
\hline$\geq 3.7 \mathrm{kPa}$ & & 89 (65-99) & $37(28-46)$ & 95 (84-99) & $19(11-29)$ & $44(35-53)$ \\
\hline$\geq 5.3 \mathrm{kPa}^{\dagger}$ & $0.78(0.65-0.92)$ & $67(41-87)$ & $83(75-90)$ & 94 (87-98) & $40(23-59)$ & $81(73-88)$ \\
\hline$>6.0 \mathrm{kPa}$ & & $56(31-78)$ & $91(86-97)$ & 93 (86-97) & $50(27-73)$ & $86(76-91)$ \\
\hline \multicolumn{7}{|c|}{ APRI $(n=122)$} \\
\hline$>0.4$ & $0.70(0.54-0.86)$ & $50(27-73)$ & $92(85-97)$ & $90(83-95)$ & $56(31-78)$ & $85(78-91)$ \\
\hline$>0.5^{\dagger}$ & & $50(26-74)$ & $94(88-98)$ & $92(85-96)$ & $60(32-84)$ & $88(81-93)$ \\
\hline \multicolumn{7}{|c|}{ FibroTest $(n=106)$} \\
\hline$>0.10^{\dagger}$ & $0.76(0.62-0.90)$ & $82(57-96)$ & $57(46-68)$ & $94(85-99)$ & $27(16-41)$ & $61(51-71)$ \\
\hline$>0.20$ & & $38(18-62)$ & 89 (81-95) & $85(76-92)$ & $47(23-72)$ & 79 (70-87) \\
\hline
\end{tabular}

Data presented as \% $(95 \% \mathrm{Cl})$. *Biopredictive, France; + Optimal cut-offs of tests defined by the maximal sum of sensitivity and specificity. AUROC Area under the ROC curve

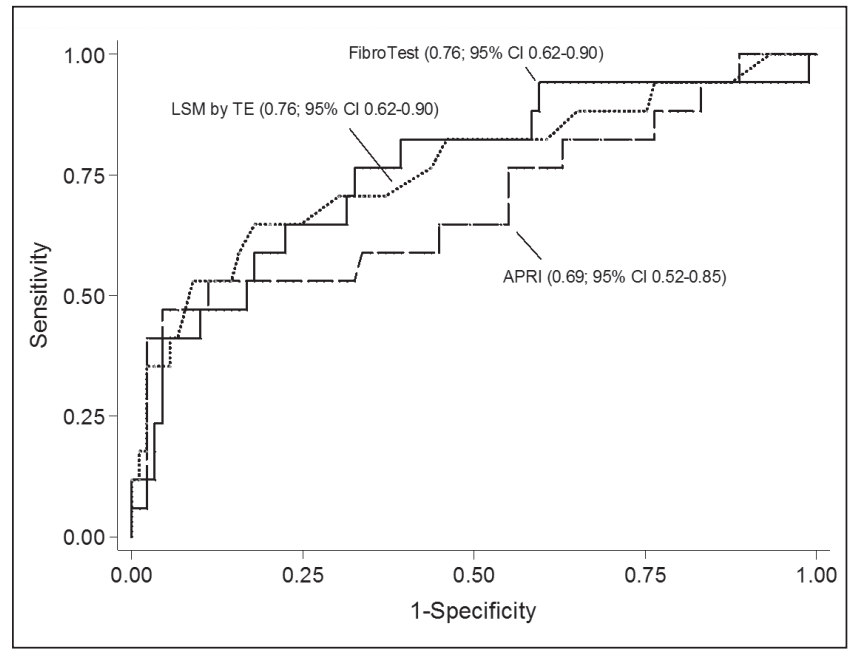

Figure 2) Areas under the ROC curve of liver stiffness measurement (LSM) using transient elastography, aspartate aminotransferase to platelet ratio index (APRI) and FibroTest (Biopredictive, France) for the detection of cystic fibrosis-related liver disease. There were no significant differences among measures among 105 patients who underwent all three tests $(P=0.64)$

0.54 to $0.86[n=122])$ and $0.76(95 \%$ CI 0.62 to $0.90[n=106])$, respectively. In the 105 patients who underwent all three tests, there were no significant differences in AUROCs for the detection of CFLD ( $\mathrm{P}=0.64$; Figure 2). Among 18 patients who underwent ARFI imaging, the AUROC of SWV for detecting CLFD was 0.72 (95\% CI 0.17 to 1.00 ).

Table 3 summarizes the operating characteristics of LSM using TE, APRI and FT for the detection of CFLD. ARFI is excluded due to the small number of patients. At an optimal cut-off value $\geq 5.3 \mathrm{kPa}$, LSM according to TE was $67 \%$ sensitive ( $95 \%$ CI $41 \%$ to $87 \%$ ) and $83 \%$ specific ( $95 \%$ CI $75 \%$ to $90 \%$ ). At a CFLD prevalence of $14 \%$, FS values below this threshold excluded CFLD (NPV) with 94\% (95\% CI $87 \%$ to $98 \%$ ) certainty. However, LSM values $\geq 5.3 \mathrm{kPa}$ were poorly predictive of CFLD (PPV 40\% [95\% CI 23\% to 59\%]). An LSM cutoff of $>6.0 \mathrm{kPa}$ was more specific (91\% [95\% CI 86\% to 97\%]), but less sensitive (56\% [95\% CI 31\% to 78\%]). At an optimal cut-off of $>0.10$, the FT was $82 \%$ (95\% CI $57 \%$ to $96 \%$ ) sensitive and $57 \%$ (95\% CI $46 \%$ to $68 \%$ ) specific for CFLD. The NPV, PPV and accuracy were $94 \%$ (95\% CI $85 \%$ to $99 \%$ ), $27 \%$ (95\% CI $16 \%$ to $41 \%$ ) and $61 \%$ (95\% CI $51 \%$ to $71 \%$ ), respectively. At an optimal cut-off of $>0.5$, the APRI was $50 \%$ (95\% CI $26 \%$ to $74 \%$ ) sensitive and $94 \%(95 \% \mathrm{CI}$ $88 \%$ to $98 \%)$ specific. The NPV, PPV and accuracy were $92 \%(95 \%$ CI $85 \%$ to $96 \%$ ), $60 \%$ (95\% CI $32 \%$ to $84 \%$ ) and $88 \%$ (95\% CI $81 \%$ to $93 \%)$, respectively.

\section{DISCUSSION}

Identifying patients who are at risk for CFLD and potential hepatic complications is an ongoing challenge. Previous studies have estimated that as many as 30\% to $40 \%$ of CF patients have some form of liver involvement, while severe CFLD with portal hypertension is believed to occur in $<10 \%$ of patients $(1,24,25)$. The first step remains identifying which CF patients have liver disease to better determine those at risk for developing serious complications. In the present population-based cohort of adults with CF, we identified a CFLD prevalence of $14 \%$. This figure is lower than previously reported, perhaps due to the population-based nature of our data. Moreover, by the time CF patients reach adulthood, some will have already succumbed to the complications of liver disease. Our data demonstrate that patients with CFLD have higher liver stiffness according to FS, APRI and FT values than those without CFLD suggesting that these noninvasive markers of liver fibrosis have a role in screening CF patients for hepatobiliary involvement. These data validate many other studies that have demonstrated the utility of these tools in liver disorders including other cholestatic conditions, nonalcoholic fatty liver disease and viral hepatitis $(9,14,20-22,26-30)$.

Our findings illustrate that LSM according to TE, APRI and FT have acceptable diagnostic performance for the detection of CFLD (AUROCs 0.70 to 0.78 ) and that none clearly outperformed the others. Measurement of SWV according to ARFI imaging had similar utility, although the small sample size limits any firm conclusions. Our data indicate that the major role of these tests in the clinical management of patients with CF is in ruling out CFLD. For example, LSMs according 
to TE $<5.3 \mathrm{kPa}$, APRI values $<0.5$, and FT values $<0.10$ excluded CFLD with $92 \%$ to $94 \%$ certainty. Given these data, there is likely little benefit of further investigation when measurements are below these thresholds. Unfortunately, the PPV of higher values was suboptimal (27\% to $60 \%$ at these diagnostic cut-offs), suggesting that additional investigations (eg, liver biopsy) may be considered in these patients to confirm significant hepatic involvement.

LSM values in patients with CFLD were significantly higher than in those without CFLD despite both groups having relatively low median TE values (6.4 $\mathrm{kPa}$ versus $3.9 \mathrm{kPa}$ [Table 2]). Other investigators have noted these small, but significant, differences. For example, Kitson et al (6) reported median LSMs of $8.1 \mathrm{kPa}$ (IQR 6.8 to $9.5 \mathrm{kPa}$ ) in adults with CFLD compared with $5.0 \mathrm{kPa}$ (IQR 4.1 to $5.6 \mathrm{kPa}$ ) in those without CFLD. Median LSM values in two other studies were $6.7 \mathrm{kPa}$ and $9.2 \mathrm{kPa}$ in patients with CFLD compared with $4.3 \mathrm{kPa}$ and $4.5 \mathrm{kPa}$ in patients without CFLD, respectively $(7,31)$. In another study, Karlas et al (12) reported a trend toward higher LSMs in patients with CFLD; however, this difference was not statistically significant, likely due to the small number of patients with CFLD $(n=14)$. In this study, TE measurements in patients with CF-related cirrhosis were found to be lower than those observed in cirrhotic patients without CF. It is, therefore, important to recognize that patients with CF may be at risk for CFLD despite having FS readings not considered to be grossly abnormal in patients with other forms of liver disease. This is not surprising considering the fact that CFLD includes a constellation of histological abnormalities above and beyond fibrosis.

Our study confirms the feasibility of LSM using TE in patients with CF. Only one patient had an unreliable LSM result, likely due to use of the FS M probe rather than the XL probe despite severe obesity (BMI $35 \mathrm{~kg} / \mathrm{m}^{2}$ ) (32). We have previously shown that patients with chronic lung disease (predominantly chronic obstructive pulmonary disease) have an increased risk for unreliable TE readings. We hypothesized that this was likely due to structural alterations in the chest wall (eg, hyperinflation) or technical difficulties with the FS procedure due to deep respirations in these patients (14). This does not appear to be a factor in patients with CF.

We have yet to complete follow-up TE measurements in our cohort, but one small study of patients with CFLD (8) reported that LSMs remained stable over a median follow-up period of nearly two years. This finding supports previous studies reporting that the development of CFLD generally occurs before 20 years of age and follows a relatively benign course in adults $(1,25,33,34)$. However, in other cholestatic liver disorders, such as primary biliary cirrhosis and primary sclerosing cholangitis, liver stiffness increases more rapidly at greater fibrosis stages $(28,30)$. It is, therefore, possible that progression of CFLD in patients with more advanced disease may occur faster than in those with milder disease. Large prospective studies examining serial TE readings will help clarify whether repeat FS assessment will be useful in the management of adults with CF.

We did not find an association between the development of CFLD and any CF-related complications (eg, pancreatic insufficiency or lung transplantation) or CFTR mutations. The underlying mechanism explaining why certain individuals with CF develop more significant liver disease than others is not clearly understood; however, one study suggests a genetic polymorphism in the SERPINA1 gene may play a role (33). A study that examined the use of these noninvasive fibrosis measurements in young patients with the SERPINA1 $\mathrm{Z}$ allele would possibly help clarify how to identify patients with CF who are at risk for progressing to severe liver disease.

Our study had several limitations. First, the definition of CFLD relied on noninvasive criteria (ie, abnormal liver biochemistry and ultrasonography), rather than liver biopsy. Nevertheless, even with histological assessment, there is no universally accepted definition of what constitutes CFLD. Moreover, many liver lesions of CF begin focally and may be missed by liver biopsy (3). Furthermore, the current consensus opinion has relied on the same noninvasive markers to define CFLD used in our study $(2,35)$. On a related note, $25 \%$ of our cohort was prescribed UDCA, including $83 \%$ of those with CFLD. This finding is relevant because UDCA has been shown to improve liver biochemistry test results and the progression to severe liver disease in patients with CF $(34,36,37)$. Therefore, the values of the noninvasive markers obtained in our study may have been affected. To date, the effect of UDCA on liver stiffness and serum fibrosis markers in patients with $\mathrm{CF}$ has not been studied. In addition, our reference standard for the definition of CFLD included abnormal liver biochemistry as one criterion. Therefore, biochemical improvement due to UDCA may have led to misclassification of CFLD in some patients. In fact, because $14 \%$ of our patients 'without' CFLD were prescribed UDCA, the prevalence of CFLD could be as high as $28 \%$. The presence of extrahepatic cholestasis in patients with CF may have also led to falsely elevated LSM using TE (38). Finally, only a small subset of our cohort underwent ARFI imaging due to limited availability during the study period. This likely explains why we failed to show a significant difference in SWV between those with and without CFLD, particularly considering the correlation between LSM measured by TE and SWV. Previous studies involving a pediatric population have shown ARFI to be useful in detecting CFLD (39-41); however, a small study failed to confirm this finding in an adult population (12). Larger studies assessing the feasibility and performance characteristics of ARFI in the detection of CFLD in adults are needed.

\section{SUMMARY}

Noninvasive markers of liver fibrosis including LSM using FS, FT and APRI appear to be useful in patients with CF, particularly in the exclusion of CFLD. Additional studies are necessary to validate measurement of SWV using ARFI, and to confirm the prognostic significance of these tools for predicting CFLD-related complications.

ACKNOWLEDGEMENTS: This study was supported in part by grants to Dr Myers from Alberta Innovates - Health Solutions (AI-HS), the Canadian Institutes for Health Research (CIHR), and the Canadian Liver Foundation.

DISCLOSURES: The authors have no financial disclosures or conflicts of interest to declare.

\section{REFERENCES}

1. Colombo C, Battezzati PM, Crosignani A, et al. Liver disease in cystic fibrosis: A prospective study on incidence, risk factors, and outcome. Hepatology 2002;36:1374-82.

2. Debray D, Kelly D, Houwen R, Strandvik B, Colombo C. Best practice guidance for the diagnosis and management of cystic fibrosisassociated liver disease. J Cyst Fibros 2011;(10 Suppl 2):S29-36.

3. Lewindon PJ, Shepherd RW, Walsh MJ, et al. Importance of hepatic fibrosis in cystic fibrosis and the predictive value of liver biopsy. Hepatology 2011;53:193-201.

4. Bravo AA, Sheth SG, Chopra S. Liver biopsy. N Engl J Med 2001;344:495-500.

5. Myers RP, Fong A, Shaheen AAM. Utilization rates, complications and costs of percutaneous liver biopsy: A population-based study including 4275 biopsies. Liver Int 2008;28:705-12.

6. Kitson MT, Kemp WW, Iser DM, Paul E, Wilson JW, Roberts SK. Utility of transient elastography in the non-invasive evaluation of cystic fibrosis liver disease. Liver Int 2013;33:698-705.

7. Friedrich-Rust M, Schlueter N, Smaczny C, et al. Non-invasive measurement of liver and pancreas fibrosis in patients with cystic fibrosis. J Cyst Fibros 2013;12:431-9.

8. Karlas T, Neuschulz M, Oltmanns A, Wirtz H, Keim V, Wiegand J. ARFI and transient elastography for characterization of cystic fibrosis related liver disease: First longitudinal follow-up data in adult patients. J Cyst Fibros 2013;12:826-7.

9. Shaheen AAM, Myers RP. Diagnostic accuracy of the aspartate aminotransferase-to-platelet ratio index for the prediction of hepatitis C-related fibrosis: A systematic review. Hepatology 2007;46:912-21. 
10. Wai C-T, Greenson JK, Fontana RJ, et al. A simple noninvasive index can predict both significant fibrosis and cirrhosis in patients with chronic hepatitis C. Hepatology 2003;38:518-26.

11. Friedrich-Rust M, Wunder K, Kriener S, et al. Liver fibrosis in viral hepatitis: Noninvasive assessment with acoustic radiation force impulse imaging versus transient elastography. Radiology 2009;252:595-604.

12. Karlas T, Neuschulz M, Oltmanns A, et al. Non-invasive evaluation of cystic fibrosis related liver disease in adults with ARFI, transient elastography and different fibrosis scores. PLoS One 2012;7:e42139.

13. Canadian Cystic Fibrosis Patient Data Registry Report 2010 <cysticfibrosisvictoria.ca/wp-content/uploads/2013/06/CPDR_ ReportE.pdf> (Accessed November 1, 2014).

14. Pang JX, Pradhan F, Zimmer S, et al. The feasibility and reliability of transient elastography using Fibroscan: A practice audit of 2335 examinations. Can J Gastroenterol Hepatol 2014;28:143-9.

15. Boursier J, Zarski J-P, de Lédinghen V, et al. Determination of reliability criteria for liver stiffness evaluation by transient elastography. Hepatology 2013;57:1182-91.

16. Imbert-Bismut F, Ratziu V, Pieroni L, Charlotte F. Biochemical markers of liver fibrosis in patients with hepatitis $\mathrm{C}$ virus infection: A prospective study. Lancet 2001;357:1069-75.

17. Poynard T, Imbert-Bismut F, Ratziu V, et al. Biochemical markers of liver fibrosis in patients infected by hepatitis $\mathrm{C}$ virus: Longitudinal validation in a randomized trial. J Viral Hepat 2002;9:128-33.

18. Poynard Patent $<$ http://patft.uspto.gov/netacgi/nph-Parser?Sect1=P TO1\&Sect $2=$ HITOFF\&d=PALL\&p=1\&u=\%2Fnetahtml\%2FPTO $\% 2$ Fsrchnum.htm\& $r=1 \& f=G \& l=50 \& s 1=6631330 . P N . \& O S=P N / 66$ 31330\&RS=PN/6631330> (Accessed November 1, 2014).

19. Myers RP, De Torres M, Imbert-Bismut F, et al. Biochemical markers of fibrosis in patients with chronic hepatitis C: A comparison with prothrombin time, platelet count, and age-platelet index. Dig Dis Sci 2003;48:146-53.

20. Myers RP, Tainturier MH, Ratziu V, et al. Prediction of liver histological lesions with biochemical markers in patients with chronic hepatitis B. J Hepatol 2003;39:222-30.

21. Lieber CS, Weiss DG, Morgan TR, Paronetto F. Aspartate aminotransferase to platelet ratio index in patients with alcoholic liver fibrosis. Am J Gastroenterol 2006;101:1500-8.

22. Kim D, Kim WR, Kim HJ, Therneau TM. Association between noninvasive fibrosis markers and mortality among adults with nonalcoholic fatty liver disease in the United States. Hepatology 2013;57:1357-65.

23. DeLong ER, DeLong DM, Clarke-Pearson DL. Comparing the areas under two or more correlated receiver operating characteristic curves: A nonparametric approach. Biometrics 1988;44:837-45.

24. Chryssostalis A, Hubert D, Coste J, et al. Liver disease in adult patients with cystic fibrosis: A frequent and independent prognostic factor associated with death or lung transplantation. J Hepatol 2011;55:1377-82.

25. Lamireau T, Monnereau S, Martin S, Marcotte J-E, Winnock M, Alvarez F. Epidemiology of liver disease in cystic fibrosis: A longitudinal study. J Hepatol 2004:41:920-5.

26. Shaheen AAM, Wan AF, Myers RP. FibroTest and FibroScan for the prediction of hepatitis C-related fibrosis: A systematic review of diagnostic test accuracy. Am J Gastroenterol 2007;102:2589-600.
27. Myers RP, Elkashab M, Ma M, Crotty P, Pomier-Layrargues G. Transient elastography for the noninvasive assessment of liver fibrosis: A multicentre Canadian study. Can J Gastroenterol 2010;24:661-70.

28. Corpechot C, Gaouar F, Naggar El A, et al. Baseline values and changes in liver stiffness measured by transient elastography are associated with severity of fibrosis and outcomes of patients with primary sclerosing cholangitis. Gastroenterology 2014;146:970-6.

29. Corpechot C, Naggar El A, Poujol-Robert A, et al. Assessment of biliary fibrosis by transient elastography in patients with $\mathrm{PBC}$ and PSC. Hepatology (Baltimore, Md) 2006;43:1118-24.

30. Corpechot C, Carrat F, Poujol-Robert A, et al. Noninvasive elastography-based assessment of liver fibrosis progression and prognosis in primary biliary cirrhosis. Hepatology (Baltimore, Md) 2012;56:198-208.

31. Rath T, Menendez KM, Kügler M, et al. TIMP-1/-2 and transient elastography allow non invasive diagnosis of cystic fibrosis associated liver disease. Dig Liver Dis 2012;44:780-7.

32. Myers RP, Pomier-Layrargues G, Kirsch R, et al. Feasibility and diagnostic performance of the FibroScan XL probe for liver stiffness measurement in overweight and obese patients. Hepatology (Baltimore, Md) 2012;55:199-208.

33. Bartlett JR, Friedman KJ, Ling SC, et al. Genetic modifiers of liver disease in cystic fibrosis. JAMA 2009;302:1076-83.

34. Desmond CP, Wilson J, Bailey M, Clark D, Roberts SK. The benign course of liver disease in adults with cystic fibrosis and the effect of ursodeoxycholic acid. Liver Int 2007;27:1402-8.

35. Colombo C. Liver disease in cystic fibrosis. Curr Opin Pulm Med 2007;13:529-36.

36. Nousia-Arvanitakis S, Fotoulaki M, Economou H, Xefteri M, Galli-Tsinopoulou A. Long-term prospective study of the effect of ursodeoxycholic acid on cystic fibrosis-related liver disease. J Clin Gastroenterol 2001;32:324-8.

37. Kappler M, Espach C, Schweiger-Kabesch A, et al. Ursodeoxycholic acid therapy in cystic fibrosis liver disease - a retrospective long-term follow-up case-control study. Aliment Pharmacol Ther 2012;36:266-73.

38. Millonig G, Reimann FM, Friedrich S, et al. Extrahepatic cholestasis increases liver stiffness (FibroScan) irrespective of fibrosis. Hepatology (Baltimore, Md) 2008;48:1718-23.

39. Behrens CB, Langholz JH, Eiler J, et al. A pilot study of the characterization of hepatic tissue strain in children with cysticfibrosis-associated liver disease (CFLD) by acoustic radiation force impulse imaging. Pediatr Radiol 2013;43:552-7.

40. Monti L, Manco M, Zupone Lo C, et al. Acoustic radiation force impulse (ARFI) imaging with Virtual Touch Tissue Quantification in liver disease associated with cystic fibrosis in children. Radiol Med 2012;117:1408-18.

41. Manco M, Zupone CL, Alghisi F, D’Andrea ML, Lucidi V, Monti L. Pilot study on the use of acoustic radiation force impulse imaging in the staging of cystic fibrosis associated liver disease. J Cyst Fibros 2012;11:427-32. 


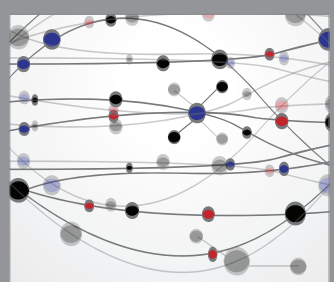

The Scientific World Journal
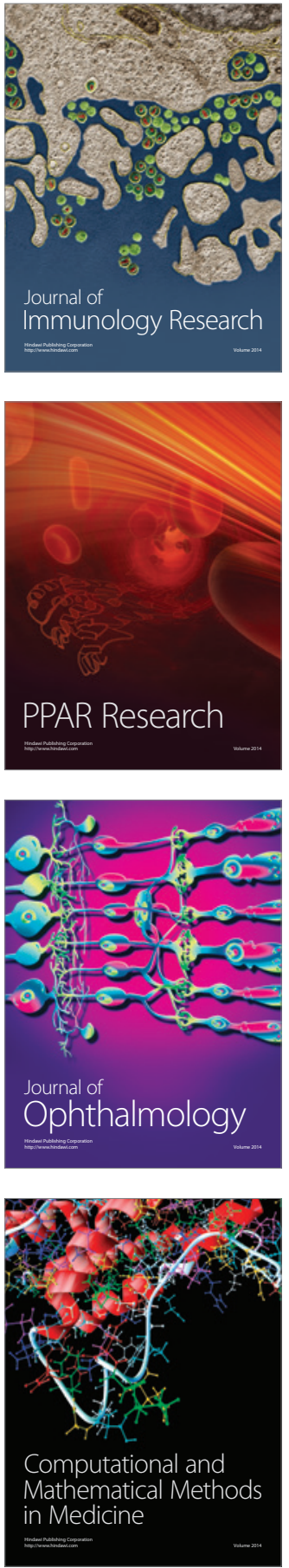

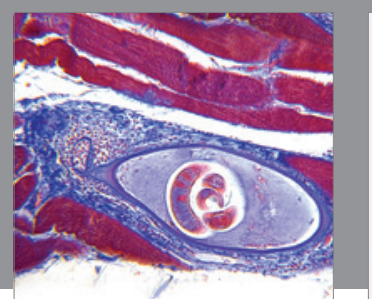

Gastroenterology Research and Practice

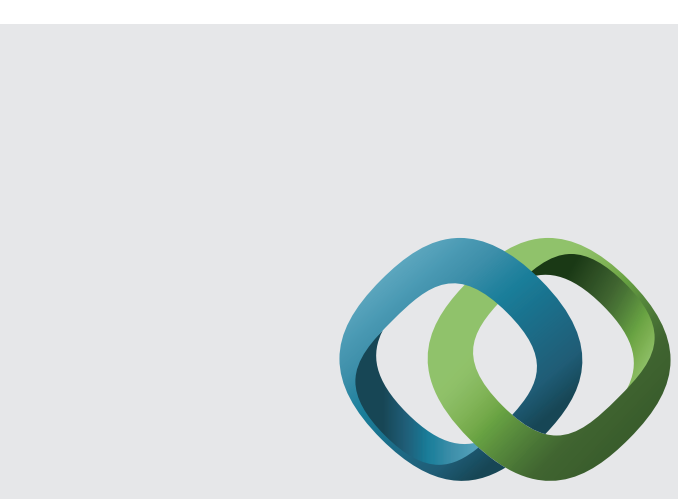

\section{Hindawi}

Submit your manuscripts at

http://www.hindawi.com
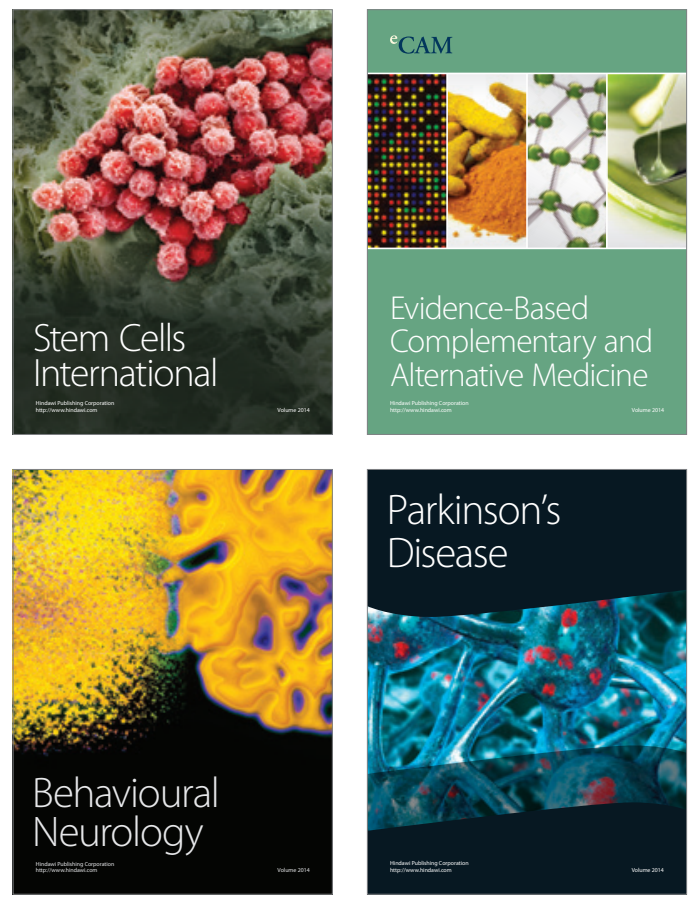
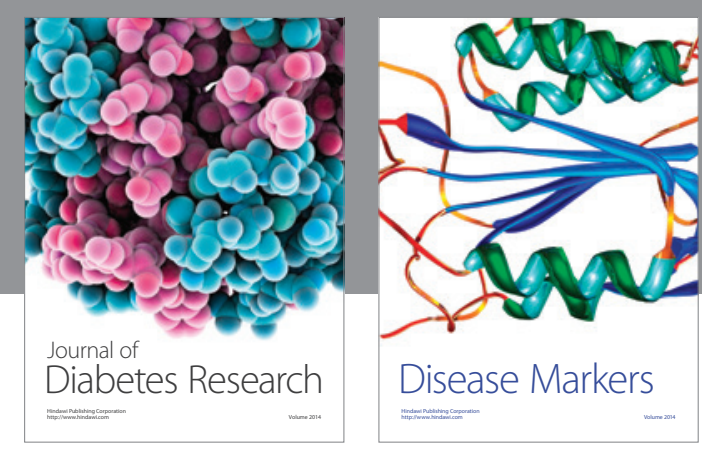

Disease Markers
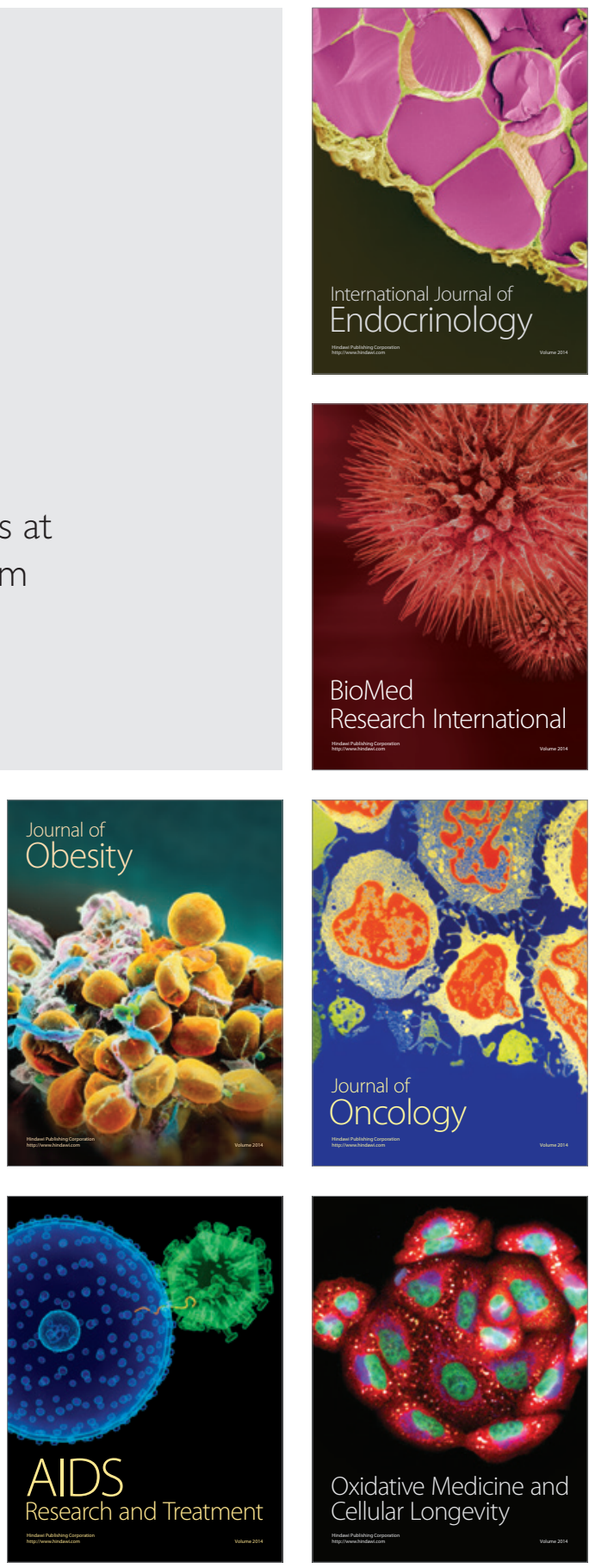